\title{
Substance Intoxication Delirium
}

National Cancer Institute

\section{Source}

National Cancer Institute. Substance Intoxication Delirium. NCI Thesaurus. Code C92640.

A disorder characterized by the acute and sudden development of changes in attention,

memory, language and/or perception that can be etiologically linked to the direct

physiological consequences of substance intoxication. 